\title{
A D2 Antagonist Enhances the Rewarding and Priming Effects of a Gambling Episode in Pathological Gamblers
}

\author{
Martin Zack ${ }^{1,2,3}$ and Constantine $X$ Poulos $^{4}$ \\ 'Clinical Neuroscience Section, Centre for Addiction and Mental Health, Toronto, ON, Canada; ${ }^{2}$ Department of Pharmacology, University of \\ Toronto, Toronto, ON, Canada; ${ }^{3}$ Department of Public Health Sciences, University of Toronto, Toronto, ON, Canada; ${ }^{4}$ Department of Psychology, \\ University of Toronto, Toronto, ON, Canada
}

\begin{abstract}
Previous research indicated shared neurochemical substrates for gambling and psychostimulant reward. This suggests that dopamine substrates may directly govern the reinforcement process in pathological gambling. To investigate this issue, the present study assessed the effects of the relatively selective dopamine D2 antagonist, haloperidol (3 mg, oral) on responses to actual gambling ( $15 \mathrm{~min}$ on a slot machine) in 20 non-comorbid pathological gamblers and 18 non-gambler controls in a placebo-controlled, double-blind, counterbalanced design. In gamblers, haloperidol significantly increased self-reported rewarding effects of gambling, post-game priming of desire to gamble, facilitation of reading speed to Gambling words, and gambling-induced elevation in blood pressure. In controls, haloperidol augmented gambling-induced elevation in blood pressure, but had no effect on other indices. The findings provide direct experimental evidence that the D2 substrate modulates gambling reinforcement in pathological gamblers.
\end{abstract}

Neuropsychopharmacology (2007) 32, 1678- 1686; doi: I0.I038/sj.npp. I 30 I295; published online 3 January 2007

Keywords: gambling; dopamine; D2; haloperidol; reward; priming

\section{INTRODUCTION}

Pathological gambling is a psychiatric disorder that often can incur devastating consequences (Morasco et al, 2006; Scherrer et al, 2005). Evidence on the neurochemical mediators of the rewarding or reinforcing effects of gambling activity itself has just begun to emerge. Recent fMRI research found that a gambling-like guessing game with monetary rewards activates the mesolimbic reward system in pathological gamblers and controls (Reuter et al, 2005). This study found that mesolimbic activation induced by the game was lower in gamblers than in controls, and the more severe the gambling pathology, the weaker the gameinduced activation. The investigators interpreted their findings as consistent with a 'reward deficiency syndrome' in pathological gamblers.

Other work has found that engaging in actual casino gambling elevates activity of the hypothalamic-pituitary axis in problem and non-problem gamblers, as reflected by increased plasma levels of norepinephrine, cortisol, and a concomitant increase in heart rate (Meyer et al, 2004). In addition, casino gambling led to elevated dopamine levels in

Correspondence: Dr M Zack, Clinical Neuroscience Section, Centre for Addiction and Mental Health, 33 Russell Street, Toronto, ON, Canada M5S 2SI, Tel: + | 416535 850।, ext. 6052, Fax: + | 416595 6618, E-mail: martin_zack@camh.net

Received I June 2006; revised 16 October 2006; accepted 2 November 2006 both groups, with higher levels emerging in the problem gamblers.

Another line of inquiry used a pharmacological crosspriming strategy to elucidate the general neurochemical mediators of gambling reinforcement (Zack and Poulos, 2004). This study found that the nonspecific dopamine agonist, $d$-amphetamine, selectively primed motivation to gamble in pathological gamblers. This finding indicates shared neurochemical substrates for gambling and psychostimulant reward. This suggests that, as in the case of psychostimulants, activation of specific dopamine substrates may directly govern the reinforcement process in pathological gambling. Evidence on this issue is critical for understanding gambling's addictive-like effects in vulnerable individuals.

A great deal of research has implicated the D2 receptor as a critical substrate modulating psychostimulant reward (Nader and Czoty, 2005; Self and Stein, 1992; Volkow et al, 1999, 2002). In addition, research on vulnerability to pathological gambling has emphasized the importance of the D2 receptor in genetic risk for this disorder (Comings et al, 1996). This is in line with other research indicating a strong link between anomalies in genes that code for the D2 receptor and risk for a variety of addictive-compulsive disorders (Blum et al, 1995, 1996).

Neuroimaging studies have consistently found deficits in D2 receptor binding (ie low availability) in individuals who manifest addictive-compulsive disorders, including cocaine and methamphetamine abuse (Volkow et al, 1990, 2001), 
heroin addiction (Wang et al, 1997), alcoholism (Volkow et al, 1996), and obesity (Wang et al, 2001). This pattern of results has fostered the hypothesis that compulsive seeking of addictive reinforcers may represent a compensatory response to genetically mediated or drug-induced deficits in D2 receptor function (eg Grace, 2000; Noble, 2000; Volkow et al, 2004).

In line with this, alcoholics with lower levels of striatal D2 receptors report greater craving and display greater cueinduced activation of the medial prefrontal cortex and anterior cingulate - brain regions involved in motivation and attention (Heinz et al, 2004). In cocaine addicts, PET research shows that exposure to cocaine cues increases endogenous dopamine activity at D2 receptors in the dorsal striatum and the magnitude of this effect predicts craving (Volkow et al, 2006). These findings suggest that individuals with low levels of striatal D2 receptors are more susceptible to cue-induced addictive motivation and that acute elevations in dopamine transmission at these receptors may directly mediate this process.

In light of this evidence on the importance of the D2 receptor in problem gambling and other addictive disorders, the present study examined the effects of the relatively selective D2 antagonist, haloperidol on responses to a brief episode of slot machine gambling in pathological gamblers and healthy controls.

\section{MATERIALS AND METHODS}

\section{Subject Characteristics}

Twenty (three female) nontreatment seeking pathological gamblers, with no comorbidity on screening tests, and 18 (four female) healthy controls, were recruited by newspaper advertisements and paid for participation. Gamblers were explicitly advised that the study was not intended to treat their gambling problems. All subjects underwent a physician's exam before testing. Sample age was 21-64 $(M=38.9$, $\mathrm{SD}=11.7)$ years. There were no group differences on any demographic variables. Neither group showed clinically relevant elevations in anxiety, depression; alcohol use or drug abuse. Mean (SD) drinks/week were 2.8 (2.4) for gamblers and 1.6 (1.9) for controls. Mean (SD) scores on the Beck Depression Inventory-short form (Beck and Beck, 1972) were 3.6 (3.1) for gamblers, and 1.1 (1.9) for controls.

All gamblers scored $\geqslant 5(M=11.0, \mathrm{SD}=4.4)$ for DSM-IV Pathological Gambling (Beaudoin and Cox, 1999). Their gambling expenses were substantial. Mean (SD) weekly expenditure on gambling was $\$ 279$ (266), corresponding to $20.3 \%$ (12.4) of their income, with an average maximum loss on a single occasion of $\$ 7563$ (22 179). Controls all scored 0 on the DSM-IV, spent $\$ 1.0$ (1.3) per week on gambling, and reported an average maximum loss on a single occasion of $\$ 7.1$ (8.4). Thus, controls were essentially non-gamblers. Among gamblers, regular gambling activities were: casino games $(15 / 20)$, slots $(12 / 20)$, sports $(8 / 20)$, horseracing $(6 / 20)$, lottery $(4 / 20)$, and bingo $(1 / 20)$.

\section{Scales and Apparatus}

Visual analog scales (VAS; 0-10; Not At All-Extreme) measured perceived Good Effects and Bad Effects of the capsule. The Addiction Research Center Inventory (ARCI; Haertzen, 1965) provided a complementary standardized measure of drug effects, and the short form of the Profile of Mood States (POMS; Shacham, 1983) measured a range of subjective states.

VAS also measured the pleasurable effects (Enjoyment, Excitement, Involvement) of the slot machine game, as well as Desire to Gamble.

A rapid reading task (Lexical Salience Task) measured reading reaction time (in $\mathrm{ms}$ ) to degraded Gambling words $\left(\right.$ eg $\left.\mathrm{w}^{\star} \mathrm{a}^{\star} \mathrm{g}^{\star} \mathrm{e}^{\star} \mathrm{r}\right) v s$ Neutral words $\left(\right.$ eg $\left.\mathrm{w}^{\star} \mathrm{i}^{\star} \mathrm{n}^{\star} \mathrm{d}^{\star} \mathrm{o}^{\star} \mathrm{w}\right)$. The task and stimuli are identical to those detailed in a previous study (Zack and Poulos, 2004). Salience is operationally defined as the difference in reading latency to Gambling vs Neutral words.

A commercial slot machine currently used in Ontario casinos ('Cash Crop'; WMS Gaming Inc., Chicago, IL) served as the motivational prime. Subjects could wager 1-45 credits/spin, and were told that they would receive a monetary bonus proportional to their final credit tally from each session.

Blood pressure was assessed with an automated wrist cuff (HEM-601 Omron Inc, Vernon Hills, IL).

\section{Selection of Haloperidol as Dopamine D2 Probe}

Haloperidol (3 mg, oral) induces $60-70 \%$ D2 receptor occupancy and reaches peak blood levels at $2.75 \mathrm{~h}$ postadministration (Nordstrom et al, 1992). Of the dopamine antagonists available for human use in Canada, haloperidol (particularly at the subclinical dose employed in this study) is the most selective for the $\mathrm{D} 2$ receptor. In vitro data from rats and cloned human cells (Arndt and Skarsfeldt, 1998; Schotte et al, 1996) show that haloperidol's affinity for D2 is 15 times greater than for D3, the dopamine receptor for which it has the next greatest affinity; 9-13 times greater than for the $\alpha-1$ adrenoreceptor; and 18-34 times greater than for the serotonin $2 \mathrm{~A}$ receptor; with no appreciable affinity for other transmitter binding sites. Studies of post-mortem human brain (Richelson and Souder, 2000) indicate modest affinity for the $\alpha-1$ adrenoreceptor $(\sim 15 \%$ of affinity for D2). A notable exception to this preferential binding profile is the sigma receptor, to which haloperidol binds with roughly equal affinity as for the D2 receptor (Schotte et al, 1996). This may contribute to its ability to quell hallucinations (cf. Keats and Telford, 1964).

\section{Procedure}

The study was carried out in accord with the ethical standards of the Helsinki Declaration (1975). After providing informed consent, subjects attended two test sessions, 1 week apart (to ensure washout), where they received $3 \mathrm{mg}$ oral haloperidol or placebo in a double-blind, counterbalanced design.

On each test session, $2.75 \mathrm{~h}$ after dosing, subjects played a slot machine with $\$ 200$ in credits in a mock-bar laboratory. They gambled for $15 \mathrm{~min}$ or until their credits were exhausted.

ARCI and POMS were administered at pre-capsule, and again immediately before the slot machine game at expected peak blood drug levels. Desire to Gamble was rated at these 
two times as well as right after the slot machine game. Pleasurable effects were measured after the slot machine game followed immediately by the Lexical Salience Task. Blood pressure was measured at 30-min intervals throughout the session.

To minimize possible residual priming effects of the slot machine, subjects remained at the laboratory for $4 \mathrm{~h}$ after testing was completed. They were assessed by a registered nurse before dismissal and sent home by prepaid taxi. Upon dismissal, subjects received a sealed $50-\mathrm{mg}$ dose of diphenhydramine (Benadryl) to use in the event of a delayed dystonic reaction.

\section{Data Analytic Approach}

Mean effects were assessed with 2 (Treatment: Drug, Placebo) $\times 2$ (Group: gamblers, controls) analyses of variance (ANOVA). Where appropriate, within-subjects' variables were included in the ANOVA (eg word condition in the Lexical Salience Task). For variables where precapsule baseline scores were available (VAS ratings of Desire to Gamble), analyses of covariance (ANCOVA) were conducted, using the baseline score as the co-variate, to control extra-experimental variance and isolate Treatment effects (Wainer, 1991).

\section{RESULTS}

\section{Effects of Capsule}

To assess the effectiveness of the blind, at the end of the study subjects were asked to report which day they believed they received the drug. A 2 (Treatment Sequence: Drug on Session 1, Drug on Session 2) $\times 3$ (Response Option: Believe Day 1, Believe Day 2, Don't Know) $\chi_{2}^{2}$ of responses in the full sample was nonsignificant, $\chi^{2}$ $(d f=2, N=20)=2.61, p>0.27$. Overall, 33/38 subjects answered 'Don't Know;' two correctly and one incorrectly reported Session 1; and two incorrectly reported Session 2. The pattern did not differ in gamblers $v s$ controls, $\chi^{2}<2.3$, $p$ 's $>0.32$, with one correct report in gamblers, and one in controls. Thus, subjects could not discriminate drug from placebo, so that any differences in response to the slot machine were not owing to the presumed effects of being under the influence of a drug on gambling reinforcement.

Table 1 shows the mean (SD) self-reported effects of the capsule on the ARCI, POMS, and VAS at $2.75 \mathrm{~h}$ after dosing (peak drug levels for haloperidol) along with pre-capsule scores for each treatment in gamblers and controls.

ARCI. A 2 (Group) $\times 2$ (Treatment) $\times 2$ (Time) $\times 7$ (Subscale) ANOVA of ARCI ratings yielded the following treatment-related effects: A significant Treatment $\times$ Time interaction, $\mathrm{F}(1,216)=5.50, p=0.025$, and a marginally significant Treatment $\times$ Time $\times$ Subscale interaction, $F$ $(6,216)=2.06, p=0.060$, with no other significant effects involving Treatment, $p$ 's $>0.50$. The Treatment $\times$ Time interaction reflected a general decline in scores from precapsule to post-capsule under haloperidol as against a general increase in scores from pre- to post-capsule under placebo. As shown in Table 1, the marginally significant three-way interaction reflected a selective reversal in the pattern of scores on the MBG sub-scale, which tended to increase from pre- to post-capsule under placebo in gamblers only, but decreased in both groups from pre- to post-capsule under haloperidol. The direction of effects and absolute effect sizes for the various Subscales are highly consistent with previous research that tested an acute 3-mg dose of haloperidol in healthy volunteers (Enggasser and de Wit, 2001; Wachtel et al, 2002). A significant main effect of Group, $\mathrm{F}(1,36)=5.46, p=0.025$, reflected somewhat higher overall mean (SD) scores, aggregated across Subscales and Treatments, in gamblers, $3.8(0.8)$, than controls, $3.2(0.8)$.

POMS. A 2 (Group) $\times 2$ (Treatment) $\times 2$ (Time) $\times 6$ (Subscale) ANOVA of POMS ratings yielded no significant effects involving Treatment, $p$ 's $>0.10$.

VAS. A 2 (Group) $\times 2$ (Treatment) $\times 2$ (Subscale) ANOVA of VAS scores yielded a marginally significant Treatment $\times$ Subscale interaction, $\mathrm{F}(1,36)=3.44, p=0.072$, with no other significant Treatment-related effects, $p$ 's $>0.56$. Table 1 reveals that this result reflected a modest but consistent increase in reported Bad Effects in each group under haloperidol vs placebo, whereas Good Effects scores did not change appreciably owing to the drug treatment.

\section{Effects of Slot Machine Game}

Self-reported pleasurable effects of game. Figure 1 shows the mean (SEM) ratings of gambling-induced Enjoyment, Excitement, and Involvement and indicates that haloperidol increased scores on each sub-scale in gamblers, but did not appear to alter scores appreciably in controls. These observations were corroborated by the analyses. A 2 (Group) $\times 2$ (Treatment) $\times 3$ (Subscale) ANOVA yielded a significant main effect of Group, $\mathrm{F}(1,36)=6.36, p=0.016$, a Treatment $\times$ Group interaction, $\mathrm{F}(1,36)=4.17, p=0.048$, and no significant higher order effects, $p$ 's $>0.50$. The Group effect reflects higher scores in gamblers than controls across Subscales and Treatments. The interaction reflects the significant increase in Subscale scores under haloperidol in gamblers but not in controls; and the lack of significant higher order effects indicates that haloperidol exerted a consistent augmenting effect across all three subscales. The mean shared variance for the three subscales was $r^{2}=0.66$, for gamblers, and $r^{2}=0.65$, for controls. Thus, a common pleasurable effect of the game accounted for about twothirds of the variance in the sub-scale scores, whereas about one-third of the variance was unique to each sub-scale.

Self-reported motivation to gamble. Figure 2 shows mean (SEM) Desire to Gamble ratings before and after the slot machine game. The figure indicates that haloperidol on its own had no effects on pre-game Desire in either group. Desire scores rose from pre- to post-game under placebo in each group; and the degree of this game-induced increase appeared to be greater under haloperidol in gamblers but not in controls. Analyses corroborated these observations.

A preliminary 2 (Group) $\times 2$ (Treatment) ANOVA of pre-capsule Desire ratings (not shown) yielded a significant main effect of Group, $\mathrm{F}(1,36)=38.39, p<0.001$, and no other significant effects, $p$ 's $>0.26$, reflecting a significantly 
Table I Mean (SD) Subjective Effects of Capsule (3 mg Haloperidol; Placebo) at Peak Blood Levels (2.75 h Post-Administration) on Sub-scales of the ARCI, POMS (short-form), and Visual Analog Scales (Good/Bad Effects; 0-10) in Healthy Control Subjects ( $n=18$ ) and Pathological Gamblers $(n=20)$

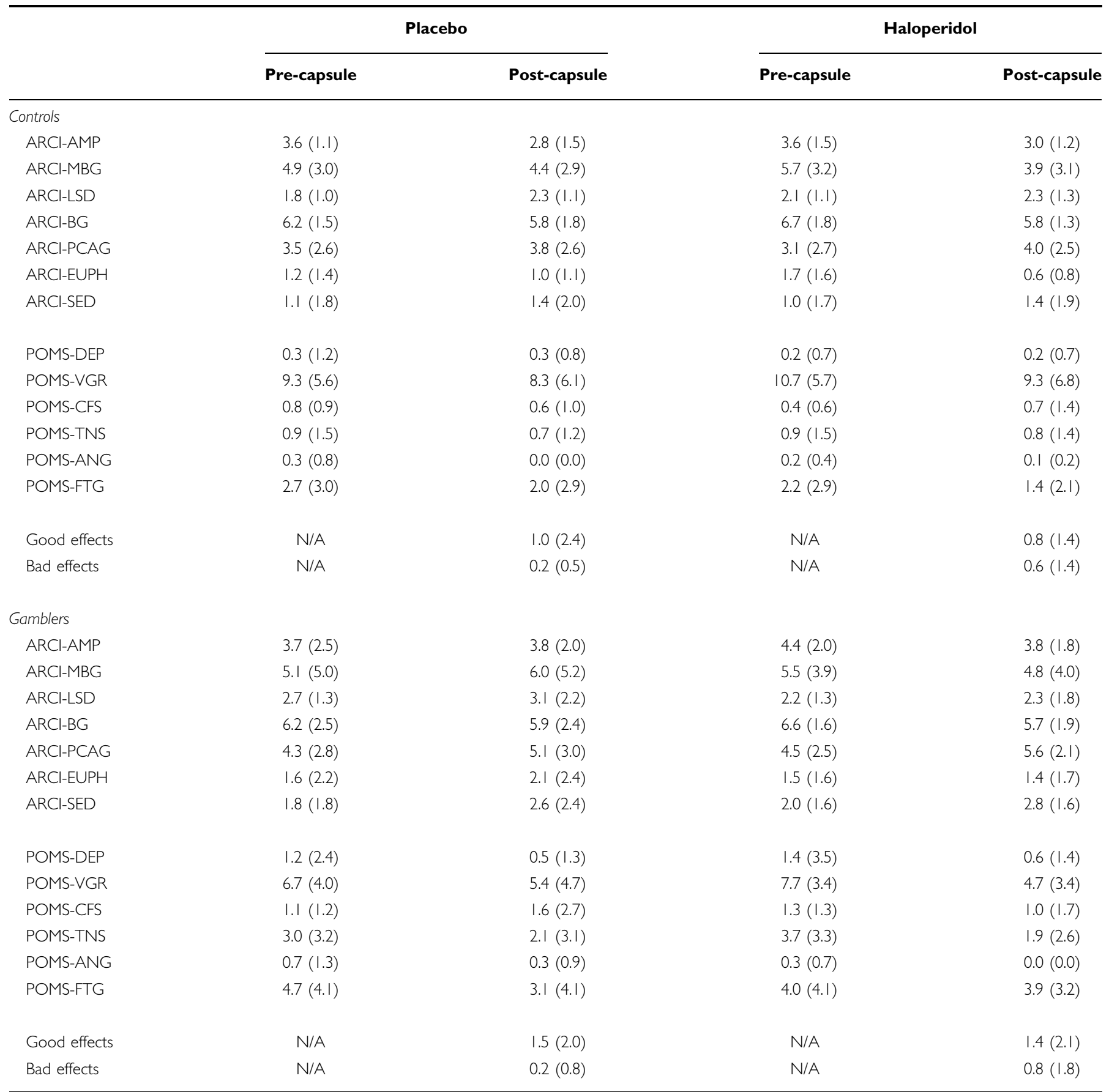

$\overline{\mathrm{ARCl}}$, Addiction Research Center Inventory, Sub-scales; AMP, amphetamine; MBG, morphine-benzedrine group; LSD, hallucinogens; BG, benzedrine group; PCAG, pentobarbital-chlorpromazine group; EUPH, euphoria; SED, sedation; POMS, Profile of Mood States (short form), Sub-scales; DEP, depression; VGR, vigor; CFS, confusion; TNS, tension; ANG, anger; FTG, fatigue.

greater mean (SD) pre-capsule baseline Desire to Gamble in gamblers, 3.6 (1.8) than controls, 0.4 (1.8) on each test session. To isolate the Treatment effect (Wainer, 1991), a 2 (Group) $\times 2$ (Treatment) $\times 2$ (Pre-Post Game) ANCOVA of Desire to Gamble scores was conducted using pre-capsule Desire scores as the co-variate. The ANCOVA yielded a significant three-way interaction, $\mathrm{F}(1,35)=4.21, p=0.048$, and a marginal main effect of Group, $p=0.056$, reflecting higher overall scores in gamblers than in controls.

Simple effects analyses found that there was no significant effect of Treatment on pre-game Desire for either gamblers or controls, $p$ 's $>0.50$. Under placebo, the game increased Desire scores in gamblers, $t(35)=6.31, p<0.001$, and in controls, $t(35)=3.90, p<0.001$. Under haloperidol, the 


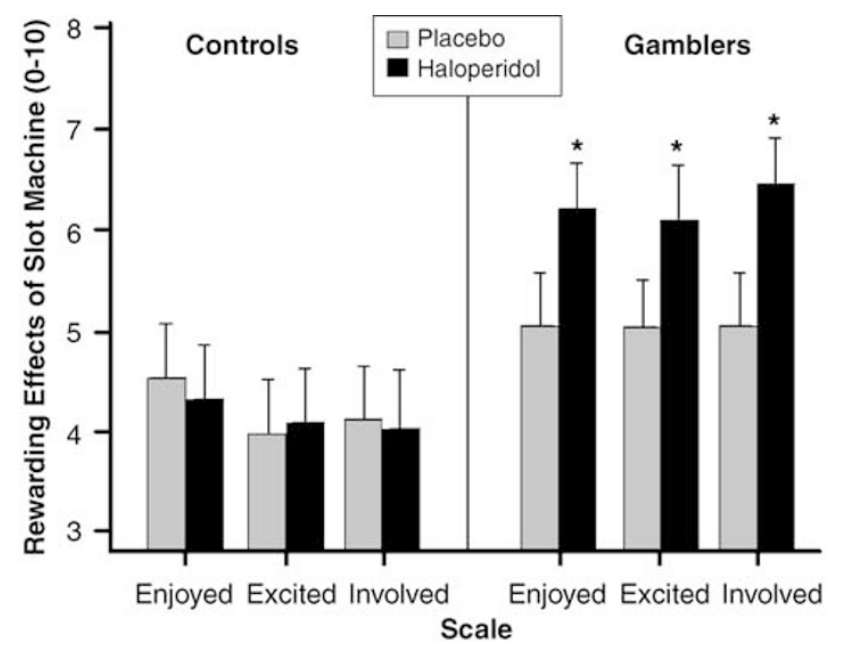

Figure I Mean (SEM) self-reported pleasurable effects of a I5-min slot machine game in healthy control subjects $(n=18)$ and pathological gamblers $(n=20)$ under haloperidol ( $3 \mathrm{mg}$, oral) and placebo. *Drug treatment effect, $p<0.001$.

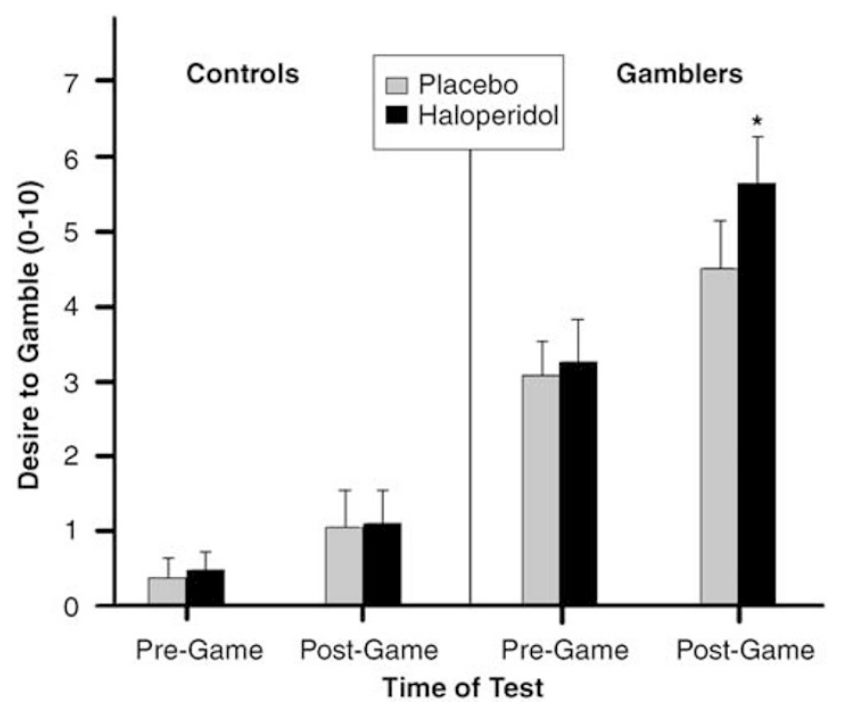

Figure 2 Mean (SEM) self-reported desire to gamble before and after a 15-min slot machine game in healthy control subjects $(n=18)$ and pathological gamblers $(n=20)$ under haloperidol ( $3 \mathrm{mg}$, oral) and placebo. *Drug treatment effect, $p<0.00$ I.

pre-post increase in Desire was significantly amplified in gamblers, $t(35)=4.13, p<0.001$, but not in controls, $p>0.50$. Thus, haloperidol selectively enhanced the priming effects of the slot machine game in pathological gamblers.

Activation of semantic networks: the lexical salience task. Table 2 reports the mean (SD) reading response time (RT; ms) scores for Gambling and Neutral control words and for the Ancillary word conditions on the Lexical Salience Task for controls and gamblers under each Treatment. The table shows that, in each group, RT was considerably slower to Neutral words than to all other types of words under placebo and haloperidol. As noted earlier, the difference in RT to a class of target words relative to motivationally irrelevant Neutral words measured salience; the greater the difference, (Neutral minus Target), the greater the salience.

A 2 (Group) $\times 2$ (Treatment) $\times 5$ (Word Condition) ANOVA yielded a significant three-way interaction, $\mathrm{F}(4,144)=3.00, \quad p=0.021$. Simple effects analyses for controls found that the RT difference from Neutral under drug vs placebo did not change significantly for Gambling words, $p>0.06$; increased for Alcohol words, $t(144)=$ 7.50, $p<0.001$; and decreased for both Positive, $t(144)=$ $7.91, p<0.001$, and Negative Affect words, $t(144)=11.08$, $p<0.001$. Thus, in controls, Gambling words were no more salient under drug than placebo; Alcohol words were more salient under drug, and Affective words, regardless of valence, were less salient under drug. Inspection of the scores for controls in Table 2 shows that, under placebo, RT to Alcohol words was unusually slow relative to the other motivationally relevant words. Thus, the relatively greater difference in RT to Alcohol vs Neutral words under haloperidol in these subjects could well have reflected regression to the mean.

Inspection of the RT scores for gamblers in the various non-Neutral word conditions under placebo reveals that they were generally quite similar. Simple effects analyses for gamblers found that haloperidol significantly increased the RT difference from Neutral for Gambling words, $t(108)=2.91, p<0.01$; and for Positive Affect words, $t(108)=5.26, p<0.001$; but did not alter relative RT to the other types of words, $p$ 's $>0.50$. Thus, the results for gamblers indicate that Gambling words and Positive Affect words were relatively more salient under haloperidol than placebo.

Physiological effects: systolic blood pressure. Figure 3 shows the effects of the slot machine game on systolic blood pressure (mmHg) under haloperidol and placebo in controls. Figure 4 shows the corresponding scores for gamblers. The figures indicate that, under placebo, blood pressure increased from pre-game to post-game in both groups. In addition, in both groups, the game-induced increase in blood pressure was greater under haloperidol. These observations were corroborated by analyses.

A 2 (Group) $\times 2$ (Treatment) $\times 8$ (Time of Test) ANOVA of systolic blood pressure scores yielded a significant Treatment $\times$ Time interaction, $\mathrm{F}(7,252)=2.64, p=0.012$, and a significant three-way interaction, $F(7,252)=2.89$, $p=0.006$. The two-way interaction reflected a consistent augmentation in the effects of Time (post-game minus pregame minimum) under haloperidol vs placebo in controls, $t(252)=6.15, p<0.001$, and in gamblers, $t(252)=5.16$, $p<0.001$. The three-way interaction reflected a group difference in the time at which the pre-game minimum occurred under each treatment. In controls, minimum blood pressure occurred $30 \mathrm{~min}$ before onset of the slot machine under placebo and immediately before the game under haloperidol; in gamblers this pattern was reversed, with the pre-game minimum occurring just before game onset under placebo, but $30 \mathrm{~min}$ before game onset under haloperidol. Notably, haloperidol augmented the gameinduced increase in blood pressure to a comparable degree in both groups. 
Table 2 Mean (SD) Reading Response Time (ms) for Word Stimuli on Lexical Salience Task Under Placebo and Haloperidol (3 mg) in Healthy Control Subjects $(n=18)$ and Pathological Gamblers $(n=20)$

Word conditions

\begin{tabular}{|c|c|c|c|c|}
\hline \multicolumn{2}{|c|}{ Test } & \multicolumn{3}{|c|}{ Ancillary } \\
\hline Gambling & Neutral & Alcohol & Positive affect & Negative affec \\
\hline 1060 (239) & |22| (359) & 1158 (317) & $1018(198)$ & I01| (247) \\
\hline 998 (237) & 1147 (319) & 1036* (229) & 995* (235) & $1007 *(216)$ \\
\hline
\end{tabular}

Gamblers

Placebo

$950(366)$

1064 (402)

$933(337)$

$945(341)$

931 (347)

Haloperidol

$895 *(261)$

$1036(349)$

$906(255)$

869* (225)

$905(281)$

${ }^{*} p<0.05$, simple effect of Treatment (Drug vs Placebo) for salience (RT difference from Neutral) for a given word condition.

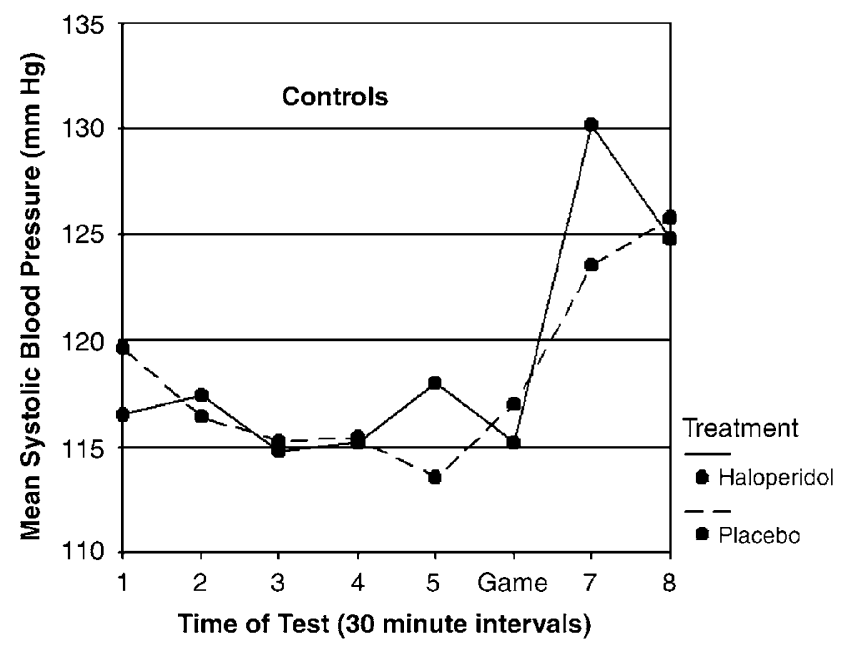

Figure 3 Mean (SEM) systolic blood pressure $(\mathrm{mm} \mathrm{Hg})$ at pre-capsule baseline and at $30 \mathrm{~min}$ intervals before and after a 15 -min slot machine game in healthy control subjects $(n=18)$ under haloperidol (3 mg, oral) and placebo.

Betting behavior in slot machine game. A series of $2 \times 2$ ANOVA's of betting behavior in the slot machine game (mean credits bet per spin, maximum credits bet per spin, final credits earned) yielded no significant effects involving Treatment, $p$ 's $>0.25$. The single significant result was a main effect of Group for mean (SD) total spins/game, which were more numerous in gamblers, 89.4 (39.4) than in controls, $60.6(41.6), \mathrm{F}(1,36)=9.57, p=0.004$.

\section{DISCUSSION}

Haloperidol, on its own, had no significant differential effects in pathological gamblers and healthy controls on subjective drug or mood effects as assessed by the ARCI, POMS, and VAS drug effect scales. In both groups, there were marginally significant effects on the ARCI MBG

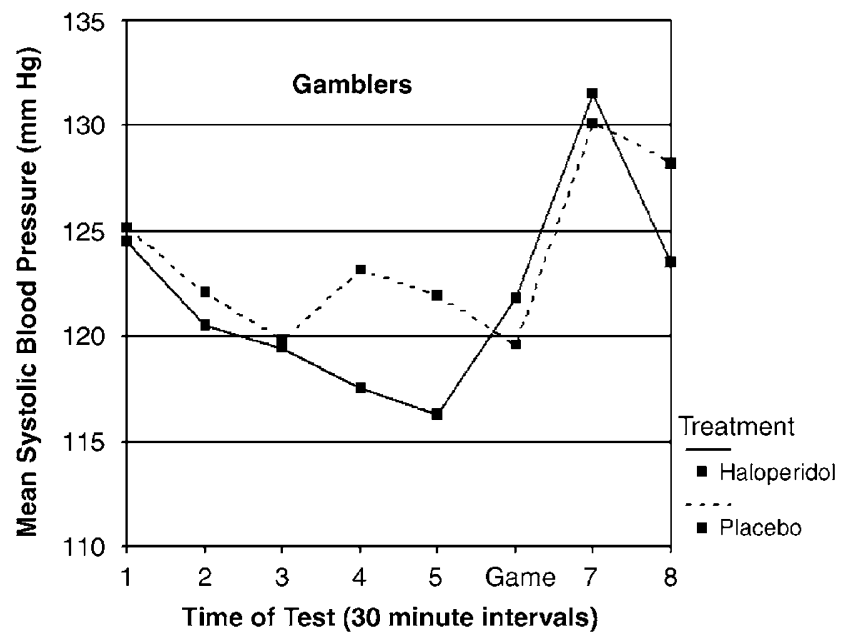

Figure 4 Mean (SEM) systolic blood pressure $(\mathrm{mm} \mathrm{Hg})$ at pre-capsule baseline and at $30 \mathrm{~min}$ intervals before and after a 15 -min slot machine game in pathological gamblers $(n=20)$ under haloperidol $(3 \mathrm{mg}$, oral $)$ and placebo.

subscale (decreased well-being) and on the VAS Bad Effects scale that were consistent with the typical effects of a neuroleptic drug. Overall, the pattern and magnitude of scores and effect sizes were highly comparable with those reported in previous studies using the same dose in physically healthy volunteers (Enggasser and de Wit, 2001; Wachtel et al, 2002).

Considering first the findings for gamblers, haloperidol augmented the pleasurable effects of the slot machine game as reflected by the Enjoyment, Excitement, and Involvement scales. The mean squared intercorrelation for the three subscales was $r^{2}=0.66$, for gamblers, indicating that a common pleasurable effect of the game accounted for about twothirds of the variance in the sub-scale scores, whereas about one-third of the variance was unique to each sub-scale.

Haloperidol on its own had no significant effect on pre-game Desire to Gamble in problem gamblers. Under 
placebo, the slot machine game increased Desire to Gamble and haloperidol significantly amplified this priming effect in gamblers. Thus, haloperidol had consistent effects across rewarding and motivational aspects of the slot machine game, a pattern that cross-validates the two types of indices. Haloperidol also enhanced the salience of Gambling words relative to Neutral words, as evidenced by faster automatically executed reading responses on the Lexical Salience Task. With respect to physiological activation, the slot machine led to a significant increase in blood pressure under placebo and haloperidol significantly augmented this effect. Thus, haloperidol increased the rewarding, priming, and physiological activating effects of gambling in pathological gamblers. Effects were clear and convergent across self-report, automatic reading responses, and blood pressure indices.

A number of results for controls were consistent with those for gamblers. First, in controls, haloperidol on its own had no significant effect on pre-game Desire to Gamble. Second, under placebo, the slot machine game primed Desire to Gamble and increased systolic blood pressure in controls. This latter finding is consistent with the previously noted findings of elevated sympatho-adrenal responses in problem and non-problem gamblers during casino gambling (Meyer et al, 2004). Finally, haloperidol augmented the pressor effects of the game in controls and the magnitude of the drug effect was quite similar to that of gamblers.

In contrast to gamblers, in controls, haloperidol did not enhance the pleasurable rewarding effects of the game, primed desire to gamble or reactivity to Gambling words on the Lexical Salience Task. Thus, in control subjects who were essentially non-gamblers, haloperidol enhancement of physiological activation appears to be dissociated from its effects on rewarding-motivational responses to gambling activity. However, control subjects did appear to find playing the slot machine to be reinforcing, as indexed by self-reported pleasurable effects of the game and the gameinduced priming of Desire to Gamble under placebo. It is unclear what accounts for the dissociation in the effects of haloperidol on the physiological and reward indices in the non-gambler controls. This raises the question of how haloperidol might affect social gamblers in this experimental paradigm. It is possible that a history of gambling and concomitant conditioned responses or tolerance may contribute to haloperidol's effects on gambling reinforcement. There is some evidence in research with animals that the dopamine system and the D2 receptor in particular play a different role in the reinforcing properties of addictive stimuli in addicted $v s$ nonaddicted subjects (cf. Dockstader et al, 2001).

The finding that partial D2 blockade enhanced the rewarding-motivational effects of gambling in pathological gamblers may seem somewhat surprising. Given the apparent neurochemical similarities between gambling and psychostimulant reinforcement (Zack and Poulos, 2004), research on the effects of dopamine antagonists on psychostimulant reward is relevant. Extensive research with animals using a variety of paradigms has found that D2 blockade consistently decreases the reinforcing efficacy of psychostimulant drugs (Amit and Smith, 1992; Bari and Pierce, 2005; Britton et al, 1991; Caine et al, 2002; Fletcher,
1998). In studies with humans, the effects of $D 2$ antagonists on psychostimulant reward have been inconsistent. Some studies have found no effect (eg Brauer and de Wit, 1997; Wachtel et al, 2002); others have found decreased psychostimulant reward (eg Gunne et al, 1972; Jonsson, 1972; Sherer et al, 1989); and one study has found increased psychostimulant reward (Brauer and de Wit, 1996). In their review of the psychostimulant literature, Brauer et al (1997) discuss the seeming lack of correspondence between the animal and human research in terms of functional dosing and a variety of methodological differences. In light of this, a dose-response assessment of haloperidol effects on gambling reinforcement would constitute a valuable extension to the present inquiry.

Evidence from neuroimaging studies, however, does appear to be congruent with the present findings for gamblers. In a series of studies, Volkow et al $(1999,2000)$ found that lower D2 receptor availability was consistently correlated with greater subjective rewarding effects of the psychostimulant, methylphenidate in healthy volunteers. In other words, the lower the availability of D2 receptors, the greater was the liking of the drug. Also, as alluded to previously, the present findings parallel an earlier 'paradoxical' finding that pre-treatment with either 1- or 2-mg of the D2 antagonist, pimozide increased discriminability and 'liking' of a $20-\mathrm{mg}$ dose of d-amphetamine in volunteers (Brauer and de Wit, 1996).

Interestingly, in a separate study, Volkow et al (2003) found that methylphenidate-induced increases in blood pressure were highly correlated with plasma epinephrine and with increases in striatal dopamine. They suggested that methylphenidate's pressor effects were partly mediated by DA-induced increases in peripheral epinephrine. This account raises the possibility that the elevation in gamblinginduced blood pressure under haloperidol in the present study may have reflected elevations in striatal dopamine with corresponding effects on epinephrine.

As noted in the Introduction, genetic studies have provided correlational evidence indicating that low D2 receptor function is a key risk factor for development of pathological gambling (Comings et al, 1996). Subsequent fMRI research with healthy volunteers found that those with the genetic variant (A1 allele) linked with low D2 receptor function displayed increased activation to anticipated rewards in reward-relevant brain regions during a simulated gambling task (Cohen et al, 2005). The present findings extend this line of inquiry using a pharmacological approach to demonstrate that low D2 receptor availability induced by a drug enhances the reinforcing effects of slot machine gambling in pathological gamblers. These results are consonant with the neuroimaging findings cited above, and provide experimental evidence for a neurochemicalbehavioral relationship that may underlie the association between anomalies in D2 receptor genes and risk for pathological gambling.

Given the apparent neurochemical similarity between gambling and psychostimulant reinforcement (Zack and Poulos, 2004), the present findings suggest that other dopamine substrates that are modulated by D2 and influence psychostimulant reinforcement, for example, D1 and $\mathrm{D} 3$ receptors $(\mathrm{Xu}, 1998)$, could well be important for gambling reinforcement. Finally, the present findings 
suggest that drugs that enhance dopamine transmission at the D2 substrate may be promising candidates for investigating medications for pathological gambling.

\section{ACKNOWLEDGEMENTS}

This research was funded by The Ontario Problem Gambling Research Centre. We thank Ms Renee Desmond for her invaluable assistance in administering all aspects of the study, and Dr Dan DiGiacomo for overseeing the medical screening and follow-up of subjects. We are grateful to Mr Michael Spohr and WMS Gaming Inc. for providing the slot machine. Neither of the authors had any conflict of interest, financial or otherwise, that might potentially bias our work.

\section{REFERENCES}

Amit Z, Smith BR (1992). Remoxipride, a specific D2 dopamine antagonist: an examination of its self-administration liability and its effects on d-amphetamine self-administration. Pharmacol Biochem Behav 41: 259-261.

Arndt J, Skarsfeldt T (1998). Do novel antipsychotics have similar pharmacological characteristics? A review of the evidence. Neuropsychopharmacology 18: 63-101.

Bari AA, Pierce RC (2005). D1-like and D2 dopamine receptor antagonists administered into the shell subregion of the rat nucleus accumbens decrease cocaine, but not food, reinforcement. Neuroscience 135: 959-968.

Beaudoin CM, Cox BJ (1999). Characteristics of problem gambling in a Canadian context: a preliminary study using a DSM-IVbased questionnaire. Can J Psychiatry 44: 483-487.

Beck AT, Beck RW (1972). Screening depressed patients in family practice. A rapid technique. Postgrad Med 52: 81-85.

Blum K, Sheridan PJ, Wood RC, Braverman ER, Chen TJ, Comings DE (1995). Dopamine D2 receptor gene variants: association and linkage studies in impulsive-addictive-compulsive behaviour. Pharmacogenetics 5: 121-141.

Blum K, Sheridan PJ, Wood RC, Braverman ER, Chen TJ, Cull JG et al (1996). The $\mathrm{D} 2$ dopamine receptor gene as a determinant of reward deficiency syndrome. $J R$ Soc Med 89: 396-400.

Brauer LH, de Wit H (1996). Subjective responses to $d$ amphetamine alone and after pimozide pretreatment in normal, healthy volunteers. Biol Psychiatry 39: 26-32.

Brauer LH, de Wit H (1997). High dose pimozide does not block amphetamine-induced euphoria in normal volunteers. Pharmacol Biochem Behav 56: 265-272.

Brauer LH, Goudie AJ, de Wit H (1997). Dopamine ligands and the stimulus effects of amphetamine: animal models versus human laboratory data. Psychopharmacology 130: 2-13.

Britton DR, Curzon P, Mackenzie RG, Kebabian JW, Williams JE, Kerkman D (1991). Evidence for involvement of both D1 and D2 receptors in maintaining cocaine self-administration. Pharmacol Biochem Behav 39: 911-915.

Caine SB, Negus SS, Mello NK, Patel S, Bristow L, Kulagowski J et al (2002). Role of dopamine D2-like receptors in cocaine selfadministration: studies with D2 receptor mutant mice and novel D2 receptor antagonists. J Neurosci 22: 2977-2988.

Cohen MX, Young J, Baek JM, Kessler C, Ranganath C (2005). Individual differences in extraversion and dopamine genetics predict neural reward responses. Brain Res Cogn Brain Res 25: 851-861.

Comings DE, Rosenthal RJ, Lesieur HR, Rugle LJ, Muhleman D, Chiu C et al (1996). A study of the dopamine D2 receptor gene in pathological gambling. Pharmacogenetics 6: 223-234.
Dockstader CL, Rubinstein M, Grandy DK, Low MJ, van der Kooy $\mathrm{D}$ (2001). The D2 receptor is critical in mediating opiate motivation only in opiate-dependent and withdrawn mice. Eur J Neurosci 13: 995-1001.

Enggasser JL, de Wit H (2001). Haloperidol reduces stimulant and reinforcing effects of ethanol in social drinkers. Alcohol Clin Exp Res 25: $1448-1456$.

Fletcher PJ (1998). A comparison of the effects of risperidone, raclopride, and ritanserin on intravenous self-administration of $d$-amphetamine. Pharmacol Biochem Behav 60: 55-60.

Grace AA (2000). The tonic/phasic model of dopamine system regulation and its implications for understanding alcohol and psychostimulant craving. Addiction 95(Suppl 2): S119-S128.

Gunne LM, Anggard E, Jonsson LE (1972). Clinical trials with amphetamine-blocking drugs. Psychiatr Neurol Neurochir 75: 225-226.

Haertzen CA (1965). Addiction Research Center Inventory (ARCI): development of a general drug estimation scale. J Nerv Ment Dis 141: 300-307.

Heinz A, Siessmeier T, Wrase J, Hermann D, Klein S, Grusser SM et al (2004). Correlation between dopamine $\mathrm{D}(2)$ receptors in the ventral striatum and central processing of alcohol cues and craving. Am J Psychiatry 161: 1783-1789.

Jonsson L (1972). Pharmacological blockade of amphetamine effects in amphetamine-dependent subjects. Eur J Clin Pharmacol 4: 206-211.

Keats AS, Telford J (1964). Narcotic antagonists as analgesics. Clinical aspects. In: Gould RF (ed) Molecular Modification in Drug Design, Advances in Chemistry, Series 45. American Chemical Society: Washington, DC. pp 170-176.

Meyer G, Schwertfeger J, Exton MS, Janssen OE, Knapp W, Stadler MA et al (2004). Neuroendocrine response to casino gambling in problem gamblers. Psychoneuroendocrinology 29: $1272-1280$.

Morasco BJ, Vom Eigen KA, Petry NM (2006). Severity of gambling is associated with physical and emotional health in urban primary care patients. Gen Hosp Psychiatry 28: 94-100.

Nader MA, Czoty PW (2005). PET imaging of dopamine D2 receptors in monkey models of cocaine abuse: genetic predisposition versus environmental modulation. Am J Psychiatry 162: $1473-1482$.

Noble EP (2000). Addiction and its reward process through polymorphisms of the D2 dopamine receptor gene: a review. Eur Psychiatry 15: 79-89.

Nordstrom AL, Farde L, Halldin C (1992). Time course of D2dopamine receptor occupancy examined by PET after single oral doses of haloperidol. Psychopharmacology 106: 433-438.

Reuter J, Raedler T, Rose M, Hand I, Glascher J, Buchel C (2005). Pathological gambling is linked to reduced activation of the mesolimbic reward system. Nat Neurosci 8: 147-148.

Richelson E, Souder T (2000). Binding of antipsychotic drugs to human brain receptors focus on newer generation compounds. Life Sci 68: 29-39.

Scherrer JF, Xian H, Shah KR, Volberg R, Slutske W, Eisen SA (2005). Effect of genes, environment, and lifetime co-occurring disorders on health-related quality of life in problem and pathological gamblers. Arch Gen Psychiatry 62: 677-683.

Schotte A, Janssen PF, Gommeren W, Luyten WH, Van Gompel P, Lesage AS et al (1996). Risperidone compared with new and reference antipsychotic drugs: in vitro and in vivo receptor binding. Psychopharmacology 124: 57-73.

Self DW, Stein L (1992). Receptor subtypes in opioid and stimulant reward. Pharmacol Toxicol 70: 87-94.

Shacham S (1983). A shortened version of the Profile of Mood States. J Pers Assess 47: 305-306.

Sherer MA, Kumor KM, Jaffe JH (1989). Effects of intravenous cocaine are partially attenuated by haloperidol. Psychiatry Res 27: $117-125$. 
Volkow ND, Chang L, Wang GJ, Fowler JS, Ding YS, Sedler M et al (2001). Low level of brain dopamine D2 receptors in methamphetamine abusers: association with metabolism in the orbitofrontal cortex. Am J Psychiatry 158: 2015-2021.

Volkow ND, Fowler JS, Wang GJ (2004). The addicted human brain viewed in the light of imaging studies: brain circuits and treatment strategies. Neuropharmacology 47(Suppl 1): 3-13.

Volkow ND, Fowler JS, Wolf AP, Schlyer D, Shiue CY, Alpert R et al (1990). Effects of chronic cocaine abuse on postsynaptic dopamine receptors. Am J Psychiatry 147: 719-724.

Volkow ND, Wang GJ, Fowler JS, Logan J, Gatley SJ, Gifford A et al (1999). Prediction of reinforcing responses to psychostimulants in humans by brain dopamine D2 receptor levels. Am J Psychiatry 156: 1440-1443.

Volkow ND, Wang GJ, Fowler JS, Logan J, Hitzemann R, Ding YS et al (1996). Decreases in dopamine receptors but not in dopamine transporters in alcoholics. Alcohol Clin Exp Res 20: 1594-1598.

Volkow ND, Wang GJ, Fowler JS, Molina PE, Logan J, Gatley SJ et al (2003). Cardiovascular effects of methylphenidate in humans are associated with increases of dopamine in brain and of epinephrine in plasma. Psychopharmacology 166: 264-270.

Volkow ND, Wang GJ, Fowler JS, Thanos PP, Logan J, Gatley SJ et al (2002). Brain DA D2 receptors predict reinforcing effects of stimulants in humans: replication study. Synapse 46: 79-82.

Volkow ND, Wang GJ, Telang F, Fowler JS, Logan J, Childress AR et al (2006). Cocaine cues and dopamine in dorsal striatum: mechanism of craving in cocaine addiction. J Neurosci 26: 6583-6588.

Wachtel SR, Ortengren A, de Wit H (2002). The effects of acute haloperidol or risperidone on subjective responses to methamphetamine in healthy volunteers. Drug Alcohol Depend 68: 23-33.

Wainer H (1991). Adjusting for differential base rates: Lord's paradox again. Psychol Bull 109: 147-151.

Wang GJ, Volkow ND, Fowler JS, Logan J, Abumrad NN, Hitzemann RJ et al (1997). Dopamine D2 receptor availability in opiate-dependent subjects before and after naloxone-precipitated withdrawal. Neuropsychopharmacology 16: 174-182.

Wang GJ, Volkow ND, Logan J, Pappas NR, Wong CT, Zhu W et al (2001). Brain dopamine and obesity. Lancet 357: 354-357.

Xu M (1998). Unraveling dopamine D3 receptor function in response to psychostimulants using a genetic approach. Ann N Y Acad Sci 844: 27-39.

Zack M, Poulos CX (2004). Amphetamine primes motivation to gamble and gambling-related semantic networks in problem gamblers. Neuropsychopharmacology 29: 195-207. 